\title{
A poesia da guerra como narrativa da memória nacional: José Craveirinha e Ana Paula Tavares
}

\author{
JeSSICA FALCONI \\ Universitá degli Studi di Napoli l'Orientale
}

\begin{abstract}
RESUMO: O ARTIGO BUSCA DESENVOLVER UMA REFLEXÃO SOBRE O GÉNERO DA POESIA COMO CONSTRUÇÃO DE UMA NARRATIVA DA NAÇÃO PÓS-COLONIAL, ATRAVÉS DA PRODUÇÃO DE MEMÓRIA INDIVIDUAL E CULTURAL NOS TEXTOS DE JOSÉ CRAVEIRINHA (MOÇAMBIQUE) E ANA PAULA TAVARES (ANGOLA).
\end{abstract}

ABSTRACT: THE PAPER BRING A REFLECTION ABOUT POETRY AS NARRATIVE CONSTRUCTION OF POSTCOLONIAL NATION, THROUGH CULTURAL MEMORY PRODUCTION IN JOSÉ CRAVEIRINHA (MOZAMBIQUE) E ANA PAULA TAVARES (ANGOLA) POEMS.

PALAVRAS-CHAVE: LITERATURA E MEMÓRIA, LITERATURA E GUERRA, JOSÉ CRAVEIRINHA, ANA PAULA TAVARES.

KEYWORDS: LITERATURE AND MEMORY, LITERATURE AND WAR, JOSÉ CRAVEIRINHA, ANA PAULA TAVARES. 


\section{very poem breaks a silence that had to be overcome}

\section{Adrienne Rich}

Nos estudos sobre a memória colectiva e suas implicações na construção das identidades de grupos, comunidades, nações e, inclusivamente, da sua relação com a História, se tem vindo a reflectir cada vez mais sobre as estratégias de representação da violência e dos traumas originados pela guerra. As memórias de guerra são de facto objecto de estudo a partir de perspectivas teóricas e disciplinares diferentes, desde as ciências humanas até à medicina. Pela sua ligação profunda com a produção de memória dos grupos e pelas suas implicações na reconfiguração contemporânea da distinção entre história e memória (TRIULZI, 2005), a representação e a memória dos conflitos são centrais nos estudos pós-coloniais na medida em que se constituem como mananciais de contra-memórias e produção de discursos outros em oposição à história oficial geralmente imposta por um grupo dominante: representar a guerra, equivale, muitas vezes, a recuperar segmentos perdidos, ocultados ou marginalizados, pelos discursos de quem detém o poder (FORTUNATI, 2008:17).

Além disto, nas sociedades pós-coloniais, a violência e os conflitos foram elementos estruturadores quer da constituição das comunidades imaginadas, que haveriam de se tornar nações, quer da constituição dos Estados independentes, a maioria deles fundados numa nova exclusão de grupos e segmentos, a quem se nega o direito à representatividade. É o caso, dentre outros países, de Angola e Moçambique, onde as guerras de libertação nacional e os conflitos civis têm marcado o seu princípio e a sua constituição como nações independentes. Como é sabido, os conflitos que se desencadearam nestes países, tiveram raízes, modalidades e implicações diferentes, que se prendem à interacção de factores históricos, geográficos e geopolíticos distintos, mas também relativos à natureza dos movimentos e dos actores em jogo e à natureza do uso da violência em contextos locais diferentes. Apesar das diferenças, em ambos os paises, a representação da guerra se prende à representação da nação pós-colonial, deixando em aberto a pergunta colocada por Geertz na sua reflexão sobre a ambiguidade do conceito de Nação: “O que é um país se não for uma nação?” (GEERTZ, 2009:33).

O reconhecimento do carácter ficcional e socialmente construído da memória (NÜNNING, 2007), tem originado uma atenção cada vez mais pro- 
funda para as relações entre memória e literatura, tornando a representação literária da violência e dos conflitos um espaço de análise da produção de memórias enquanto forma de renegociação identitária. Se, por um lado, o acto narrativo é muitas vezes um exercício da memória (MALDONADO 2005:147), por outro lado, toda a produção de memória implica uma dimensão narrativa, precisamente pela sua natureza ficcional.

A reflexão sobre as representações da guerra na literatura moçambicana e angolana e as suas implicações na construção da identidade nacional é uma linha de pesquisa bastante actual nos estudos literários e culturais da área ${ }^{1}$. A inclusão da produção poética no conjunto das "narrativas" da nação, se por um lado remete para uma generalizada dissolução de fronteiras entre géneros literários, produzida nas literaturas surgidas em contextos coloniais e póscoloniais, por outro lado enquandra-se nas modalidades e condições específicas da produção de memória (leia-se, produção de narrativas) nas literaturas moçambicana e angolana.

Nos estudos das relações entre literatura e memória, Vera e Ansgar Nünning identificam algumas noções e usos da memória na literatura que podemos detectar na poesia moçambicana e angolana da época pós-colonial, nomeadamente: 1) a construção da memória literária, através da prática intertextual; 2) a noção de género literário como repositório de memória cultural; 3) a função da literatura como ferramenta de memória individual e cultural (NÜNNING, 2007:566). Com efeito, apesar do processo de singularização destas literaturas (ROSÁRIO, 2007:151), decorrente do desaparecimento do discurso poético que promovia a identidade nacional, em ambos os países os poetas do pósindependência trabalham em diálogo com a tradição literária, tornando o género da poesia um espaço onde guardar a memória cultural e literária da Nação.

Se como afirma Cármen Tindó Ribeiro Secco (2008), a poesia moçambicana da década de 80, inaugurada por Monção, de Luís C. Patraquim, e posteriormente dinamizada pela AEMO e pela revista Charrua, envereda pelo caminho do sonho e do amor para reagir à decepção do projecto nacionalista e às atrocidades da guerra, por outro lado, a relação com o "chão" da tradição literária,

1. Assinalamos o I e II Seminário sobre Literatura, guerra e paz: discursos da memória realizados na USP em 2007 e na Universidade Politécnica de Moçambique em 2008, respectivamente. Os dois seminários pretendiam debater, numa perspectiva comparativa, as rupturas e continuidades da situação colonial e a interacção entre literatura, história e memória, na construção da identidade cultural e das imagens do estado. 
manifesta-se na reelaboração de propostas estéticas anteriores e no permanecer de um olhar para a realidade do país recém-nascido, como compromisso ético subjacente a toda a palavra literária. Por outras palavras, o processo de esbatimento do cânone revolucionário para a construção de novos espaços poéticos produz-se entre a inovação temática e a apropriação da consciência dos valores estéticos revelados pela obra de autores como Knopfli e Craveirinha.

Um processo análogo e, ao mesmo tempo, marcadamente distinto, dá-se na poesia angolana posterior à independência. Repercorrendo as etapas deste processo, dinamizadas pela criação das "Brigadas Jovens da Literatura" e pelo aparecimento de outros grupos e revistas, como o grupo Ohandjandji e a Revista Archote, Leite defende que nos anos 80, se inicia um fenómeno de apropriação e releitura das escritas fundadoras do corpus literário nacional, originando o que na actualidade se revela como um processo de "(des)continuidade simbiótica" com o passado literário (LEITE, 2004:25). Na reconfiguração deste laço com a tradição, Inocência Mata vê uma maior intervenção da consciência subjectiva, como mediadora da nova maneira de encarar a Nação, e as suas hipóteses de existência como espaço de cidadania, através da reconstituição de Angola como espaço cultural. O envolvimento ideológico das novas gerações de escritores continua segundo o que Mata define como um processo de "internalização do olhar" sobre as novas relações de poder (MATA, 2006:25-27).

Nestas dinâmicas de "descontinuidade simbiótica" em relação à poesia fundadora da angolanidade e da moçambicanidade, a poesia pós-colonial vai configurando-se como repositório da memória literária e cultural da Nação, num processo de "canonização" interna que antecipa e, posteriormente, dialoga com a institucionalização do cânone e das histórias literárias operadas pela crítica, ou seja, mais uma das "narrativas" da memória literária identificada por Vera e Ansgar Nünning (p. 573). De facto, a prática frequente da intertextualidade, tal como o uso de outros recursos típicos do género da poesia (dedicatórias, epígrafes etc.), contribuem à criação de uma memória literária nacional, institucionalizada posteriormente pelos estudos literários que, por sua vez, participam na narração da identidade nacional. Ao mesmo tempo, o traço da descontinuidade aponta para uma apropriação crítica destes cânones, no intuito de abrir caminho para novas reconfigurações identitárias.

A maior intervenção da consciência subjectiva na poesia angolana, tal como a viragem lírica da poesia moçambicana, apontam para a emergência de 
uma subjectividade poética pós-colonial, que já não se afirma como colectiva: nas nações desmembradas pelas guerras, cabe ao olhar e à memória individual a tentativa de "contar" os fragmentos da Nação. Apesar das tendências comuns, é um facto que, como afirma Livia Apa em relação à literatura angolana, "cada autor é um universo único" e a reconstrução de um espaço partilhado se dá na descrição "da sua cartografia íntima” (APA, 2006:65) ${ }^{2}$ - nesta perspectiva, caberia perguntar-nos se no contexto destas duas literaturas, a poesia não estará a desenvolver uma função análoga, latu sensu, à das narrativas autobiográficas e dos romances históricos, isto é, a função de géneros par excellence ligados às "ficções" da memória individual e colectiva.

A temática da guerra e da destruição do espaço nacional aparece na poesia moçambicana em autores como Eduardo White, Heliodoro Baptista, Hélder Muteia, entre outros. Na maioria destes autores, a guerra é o doloroso contraponto do vector principal da sua poesia, ou seja, o amor. Na poesia de Eduardo White, como defende Rita Chaves, o amor e a morte são forças em oposição numa dialéctica atormentada e criativa entre a procura pelo espaço da individualidade e a impossibilidade de apagar o olhar para o espaço público marcado pelo horror (CHAVES, 2005:174-75). Reformulando a vertente amorosa e erótica de um Craveirinha ou de um Virgílio de Lemos, que na poesia deles se aliava à celebração e à construção do sonho nacional, White tenta resgatar, pelo amor erótico e humanitário, a paisagem de fundo da nação em guerra. Na sua poesia, o heroísmo nacionalista é reconfigurado como heró́smo do amor, derradeiro espaço de vitalidade onde se recuperar uma dimensão humana para o dia-a-dia. Também na poesia de Heliodoro Baptista, a preocupação com a realidade da guerra é constante, exprimindo-se através de um olhar, que se movimenta entre as pessoas e a paisagem, à procura de um sentido e de um futuro, em diálogo com o amor.

É evidente, portanto, que a abordagem do tema da guerra na poesia póscolonial se insere nas tendências inauguradas pela década de 80, tratando-se de uma incorporação geralmente fragmentária, feita de imagens, alusões e metáforas que revelam a preocupação constante com o papel da poesia, do amor e de outros possíveis recursos numa nação em guerra.

2. A reflexão de Livia Apa sobre o tema da guerra na literatura angolana insere-se numa mais ampla investigação de referência, apresentada também em congressos diversos. 
Neste contexto, o conjunto de 40 poemas publicados em 1997 sob o título de Babalaze das Hienas por José Craveirinha, constitui um caso singular, por várias razões. Em primeiro lugar, o poeta representa, ele próprio, um arquivovivo da memória cultural e literária da nação moçambicana, por ser uma das vozes fundadoras do discurso da identidade colectiva. Por consequência, em Babalaze das hienas o griot-Craveirinha revela o desenvolvimento de uma plena consciência da dimensão pós-colonial, ao enfrentar a desilusão do sonho nacionalista e as profundas contradições da realidade do país independente.

Em segundo lugar, Babalaze das Hienas é um caso invulgar de uma obra poética explicitamente dedicada ao tema do conflito civil em Moçambique. Trata-se de uma obra que dialoga com a colectânea de poemas Maria, de 1998 (LEITE, 2007:87), mas se na poesia anterior a celebração do amor aliava-se à exaltação da identidade nacional, a poesia pós-colonial reformula esta ligação pelo viés da negatividade: a morte do amor acompanha o desmembramento da nação perpetrado pela guerra formando uma unidade entre espaço público e privado.

Como observaram Leite (2007:90) e Secco (2008:324), a narratividade da poesia de Craveirinha produzida antes da independência marca também $B a$ balaze das hienas, através de algumas marcas narrativas, como a presença de personagens ou a organização espacio-temporal. Contudo, o estilo narrativo, resultante também da apropriação da linguagem-manifesto modernista, desaparece para se restaurar o registo fragmentário típico da lírica. O efeito de narratividade constrói-se agora através do papel que o escritor assume: o de testemunha e narrador de histórias e acontecimentos traumáticos, cujos protagonistas são pessoas comuns, as suas vidas e corpos destroçados. A memória da guerra produz, portanto, uma narrativa da nação que se compõe de múltiplos dramas individuais, reconstituindo o único espaço partilhado ainda possível: a dimensão do sofrimento.

Dizer da guerra e dos traumas de guerra implica um discurso sobre a centralidade do corpo: o trauma, para Assmann, é principalmente uma inscrição corpórea que se recusa a traduzir-se em palavra (2002:310). Na reflexão sobre a guerra, o corpo é central também por ser uma categoria não apenas biológica, mas também cultural, social, política, que acaba por ser investida na sua totalidade pela violência dos conflitos (FORTUNATI et ali, 2008:11). A destruição dos corpos implica e traduz forçosamente a destruição de um corpo colectivo maior e, como afirma Pedro Rosa Mendes, de uma rede de coordenadas e refe- 
rências em que se funda e se constrói constantemente o indivíduo, já que "cada homem é um sítio. Um sítio, um ponto no mapa, um ponto no cruzamento de todas as coordenadas possíveis: culturais, políticas, familiares, étnicas, éticas, religiosas, profissionais, sociais, etc" (MENDES, 2005:71-72).

A destruição dos corpos individuais e do corpo colectivo da nação é o que Craveirinha testemunha em Babalaze das hienas (LEITE, 2007:89), onde todas as referências, que definem os indivíduos, são totalmente subvertidas pela violência da guerra. A guerra inscreve-se no corpo físico dos protagonistas, que não se pode pensar separado do seu corpo socializado, sendo o corpo "o interface perfeito entre natureza e cultura, entre indivíduo e sociedade" (ALMEIDA, 2004:28). Esta inscrição da guerra no corpo do indivíduo altera e subverte as suas relações com os outros, com o espaço, e com a sua própria subjectividade, que é corpo também. Os títulos dos poemas logo revelam a presença de corpos mutilados ( $O$ seio; Prótese bucal; $A$ boca). A denúncia dos actos contra os corpos alia-se à representação do esvaziamento dos códigos culturais, familiares, profissionais ou simplesmente dos hábitos do dia-a-dia, da vida íntima e do tempo livre das pessoas.

Na relação entre os títulos e os textos, intensifica-se o efeito de desumanização, ao serem associadas as representações dos massacres a situações da vida normal: é o caso de poemas como "Cesarianas", "Manicuros", "Barbearia", onde estas profissões e acções relacionadas com o corpo, são reinvestidas de uma função marcadamente violenta. Em Núpcias da guerra, o massacre de uma menina de onze anos é reconstruído através de referências aos rituais do casamento: "Sogro à força no lobolo da guerra/levado ao longo dos infernos/ cómoda sumaúma nupcial/do mato" (p. 8); em Mina anti-pessoal, o absurdo da mutilação, causada pelas minas é reforçada pelo facto de o protagonista do poema ser "O avançado Jossias "Ponta Esquerda" / terror dos guarda-redes/ agora já possui três pés / mas não chuta com nenhum” (p. 22). Esta estratégia de intensificação do absurdo da guerra chega a um clímax no poema Outra Beleza, que revela a subversão de todos os padrões humanos, operada pela violência. Neste poema, o estranhamento é criado pela oposição entre as duas estrofes, de que o título fornece a chave de leitura: "Uns exibem insólitos perfis/de outra beleza/maquilhada/no mato/Ou/do viés/ou de frente/perfeitos modelos de caveira/desfilam sem nariz" (p. 25). A ironia que investe os poemas traduz a percepção de um mundo sem sentido, onde toda a lógica da 
vida foi apagada. O país é um grande corpo mutilado, revelando a destruição de toda a hipótese de nação, a nível territorial, social, cultural e político.

Se na poesia de Xigubo e Karingana ua karingana a nomeação dos lugares de Moçambique criava um espaço de reconhecimento colectivo, necessário à luta anticolonial, em Babalaze das bienas as referências a lugares, estradas ou aldeias, traduzem um mapa de linhas de fogo e fronteiras entre a vida e a morte, uma vez que representam uma característica comum a muitos conflitos, que é o contraste profundo entre as cidades e o resto do país. A paisagem não urbana, recriada pelas frequentes alusões a elementos como o mato, as estradas e carreriras do interior, vem a ser o cenário principal da violência da guerra. Em Menus, este contraste é reforçado pela oposição entre as duas estrofes, e pelo uso de registos linguísticos diferentes, criados através do léxico: "Leves/e frescas/camisas à sport/voltam a gozar o lazer/das cidades. //Entretanto, aquelas tristonhas titias/aqueles macambúzios vovós-ninguéns/e aqueles mamparras mufaninhos/ na cinegética rural/constam crus/em suculentos/menus das feras" (p. 20). No espaço em branco entre as duas estrofes, cabe o sonho falhado da nação, ou seja, uma utopia inviabilizada pela longa babalaze das bienas, durante a qual "sobrevivos moçambiquicidas/imolam-se mesclados/ no infuturo" (p. 50).

De corpos feridos é feita também a poesia de Ana Paula Tavares, que se insere no panorama da poesia angolana pós-colonial como um discurso marcadamente feminino, em que o corpo se manifesta nos seus múltiplos sentidos. Como noutros autores angolanos da mesma época, o cenário da guerra aparece na sua poesia sob forma de fragmentos e alusões, e pela representação de um mundo à beira do nada e do apagamento da existência. Em O lago da lua (1999), as imagens do corpo social fragmentado aparecem na representação do seu elo mais frágil e desprotegido, depositário de outro "infuturo": "Olhame p'ra estas crianças de vidro/cheias de água até às lágrimas/enchendo a cidade de estilhaços/procurando a vida/nos caixotes do lixo" (p. 35).

O livro testemunha também a presença de outro espaço-tempo de Angola, o dos povos pastores do sul, onde a percepção do conflito civil está associada, como esclarece Ruy Duarte de Carvalho (2002), a uma reactualização de memórias, que remonta à época colonial, e de práticas ligadas às dinâmicas das sociedades pastoris, como o roubo do gado: "Vieram muitos/à procura de pasto/traziam olhos rasos da poeira e da sede/e o gado perdido [...] Partiram com olhos rasos de pasto/limpos de poeira/levaram o gado gordo e as raparigas" (p. 27). 
Se os gritos das vítimas e os uivos das hienas marcam a sonoridade do país retratado em Babalaze das hienas, o mundo da poesia de Ana Paula Tavares encontra-se ameaçado pelo silêncio, ou seja, "a negação da palavra, a repressão ou o óbito da linguagem, incluindo, obviamente o atentado contra essa narrativa íntima a que chamamos memória" (MENDES, 2006:19). Em Dizes-me coisas amargas como os frutos (2001) o silêncio investe os indivíduos e a paisagem, onde a perda da voz e da língua traduz o esvaziamento identitário originado pela destruição da rede de referências: "Amado, onde perdeste tua língua de metal/a dos sinais e do provérbio/com o meu nome inscrito" (p. 9); e "A mãe preparou as palavras devagarinho/mas o que saiu da sua boca/ não tinha sentido" (p. 43). Essa perda da voz e da palavra associa-se à perda de hábitos, códigos e rituais trazidos pelas mudanças causadas pela guerra, mas a própria enumeração e nomeação desta perda, é uma estratégia para guardar a sua memória: "A mãe vinha sozinha sem o cesto e o peixe fumado/a garrafa de óleo de palma e o vinho fresco das espigas vermelhas [...]" (p. 42). No poema $O$ cercado, a poesia faz-se fala, diálogo e interrogação na tentativa de restaurar a palavra e, com ela, a memória dos códigos e das relações, que o isolamento e o silêncio da guerra apagam, para se reconstruírem, através da fala, as coordenadas perdidas:

De que cor era o meu cinto de missangas, mãe/feito pelas tuas mãos/e fios do teu cabelo/cortado na lua cheia/guardado do cacimbo/no cesto trançado das coisas da avó/Onde está a panela do provérbio, mãe/a das três pernas/e asa partida/que me deste antes das chuvas grandes/no dia do noivado/De que cor era a minha voz, mãe/quando anunciava a manhã junto à cascata/e descia devagarinho pelos dias. (p. 23)

Ao interrogar-se sobre um tempo e um mundo que já não existem, a poesia faz-se exercício da memória, na tentativa de refundar um espaço perdido, simultaneamente individual e colectivo, revelando o laço imprescindível entre passado e futuro: "Onde está o tempo prometido p'ra viver, mãe/se tudo se guarda e recolhe no tempo da espera/p'ra lá do cercado”. O tempo prometido pela poesia fundadora da nação é agora o tempo da espera da literatura angolana pós-colonial, esse tempo de silêncio que "é um excesso de passado que não passa" (APA, 2006:63). Nesse tempo e nesse espaço, que já perderam a sua substância de categorias comensuráveis, se pensarmos a 
guerra como sistema de destruição, e apagamento dos corpos e dos lugares, a escrita de Ana Paula Tavares é uma tentativa de reconstituir os corpos e os lugares como domínios de significação, através da sua reinscrição numa rede de referências, relações e coordenadas, que devolvem sentido e humanidade aos indivíduos e à colectividade. Trata-se de uma rede que "primeiro deixou de ser percorrida, depois deixou de ser ensinada, finalmente deixou de ser recordada" (MENDES, 2006:78). É pensando neste apagamento da rede de referências que Pedro Rosa Mendes aproxima Angola a um Não-Espaço, em oposição ao Lugar Antropológico teorizado por Marc Augé: Angola como espaço "anti-identitário, anti-relacional, talvez anti-histórico".

A poesia de Ana Paula Tavares trabalha este espaço/não-espaço angolano, no intuito de reencontrar a escala possível para refazer o mapa, juntar os fragmentos e os resíduos que ficaram da tentativa de construção da Nação levada a cabo pela geração fundadora da angolanidade. O objectivo é reconstruir a rede de referências, voltando a percorrê-la, ensiná-la, e sobretudo recordá-la, a partir do corpo como dispositivo de memórias íntimas e partilhadas: "Meu corpo é um grande mapa muito antigo/percorrido de desertos, tatuado de acidentes/habitado por uma floresta inteira/um coração plantado/dentro de um jardim japonês / regado por veias finas/com um lugar vazio para a alma" (TAVARES, 1999:35).

De acordo com Rita Monticelli, para as mulheres e outros grupos não dominantes, o corpo é também um palimpsesto de memórias controversas, cuja transmissão constitui um exercício de desconstrução e reconstrução de identidades (2007:612). Neste sentido, toda a poesia/política do corpo de Ana Paula Tavares reaviva memórias e narrativas minoritárias, que devolvem espessura aos tempos e aos espaços angolanos, reconstruindo mapas e "passados subalternos", ou, como diria Ruy Duarte de Carvalho, múltiplas temporalidades. Em Ex-votos, onde "o tempo pode medir-se/no corpo" (2003:13), a palavra reinveste de sentido o território, recuperando mapas sepultados, que apenas o olhar e a leitura da memória, podem devolver à História. A rede reconstrói-se, volta a ser "ensinada" e, sobretudo, recordada, recompondo mais uma das possíveis narrativas da Nação, "uma especial cartografia de sinais, histórias acontecidas" (p. 9).

Nestes poemas, a imagem da Nação é um espaço-tempo do nada, onde a palavra procura e reinterpreta as cicatrizes, para reintroduzir o país num ciclo de significação vivificadora. Trata-se, talvez, da imagem de "Angola na guerra", para usar uma expressão de Ruy Duarte de Carvalho, que sugere "fazer tran- 
sitar a questão do enunciado de uma categoria analítica, Angola como Estado ou como país, para uma categoria empírica: Angola como referente semântico a querer dizer os Angolanos" (2008:113). Respondendo, de certo modo, à pergunta de Geertz, Ruy Duarte de Carvalho propõe uma formulação alternativa à noção de Nação, que reflecte a produção da memória operada pela poesia: a nação como conjunto de pessoas em busca do direito à cidadania.

$\mathrm{Na}$ distância criada pela paz, que no caso de Angola é "uma missão de resgate cartográfico" (MENDES, 2006), o espaço-tempo da guerra é novamente equacionado a partir do lugar do "depois", em Manual para amantes desesperados (2007): "De onde eu venho o medo/já foi a própria casa/um gesto de sombra a palavra/agora canta-se devagarinho/pode beber-se do musgo/lágrimas amargas de sede" (p. 20-21).

Entre as "lágrimas amargas de sede" de Ana Paula Tavares e os "moçambiquicídas do infuturo" de José Craveirinha, mede-se a distância de histórias, geografias, gerações, sonhos e utopias, feridas. Mede-se também a distância entre as estratégias de reactivação da memória cultural e literária de que o género da poesia se faz dispositivo e repositório. Trata-se de uma distância cuja leitura e compreensão é uma oportunidade para se criarem novas redes de sentidos, novos lugares éticos para os referentes semânticos que Ruy Duarte de Carvalho substituiu à categoria da Nação, ou seja, os indivíduos como sujeitos de cidadania. O nosso desafio.

\section{Referências Bibliográficas}

AGAZZI, Elena; FORTUNATI, Vita Memoria e saperi: percorsi transdisciplinari. Roma: Meltemi, 2007.

ALMEIDA, Miguel Vale de. "O manifesto do corpo", Revista Manifesto 5, 17-35, 2004 APA, Livia (org. ) Angola e Mozambico: scritture della guerra e della memoria. Roma: Aracne, 2006. ASSMANN, Aleida (1999), Erinnerungsräume. Formen und Wandlungen des kulturellen. Gedächtnisses (trad. it. , 2002, Ricordare. Forme e mutamenti della memoria culturale. Bologna: Il Mulino)

CARVALHO, Ruy Duarte de. "Guerra e pace nel sudovest dell'Angola". In Maria Cristina Ercolessi (org. ). I signori della guerra. Stati e micropolitica dei conflitti. Napoli: L'Ancora del Mediterraneo, 271-280, 2002. A Câmara, a escrita e a coisa dita. Lisboa: Cotovia, 2008. 
CHAVES, Rita. Angola e Moçambique. Experiência Colonial e Territórios Literários. São Paulo: Ateliê Editorial, 2005.

CRAVEIRINHA, José. Babalaze das Hienas. Maputo: Alcance, 2008.

FORTUNATI et ali. Conflitti. Strategie di rappresentazione della guerra nella cultura contemporanea. Roma: Meltemi, 2008.

GEERTZ, Clifford. Welt ins Stüchen. Kultur und Politik am Ende des 20. Jahrhunderts, (trad. it. Mondo globale, mondi locali. Cultura e politica alla fine del ventesimo secolo. Bologna: Il Mulino),1996.

LEITE, Ana Mafalda. "Tópicos para uma História da Literatura Moçambicana”, in Margarida Calafate Ribeiro, Maria Paula Meneses (orgs). Moçambique: das Palavras Escritas. Porto: Afrontamento, 2008, 45-75.

"Exile and Death in José Craveirinha's Later Poetry", Research in African Literatures, 38(1), 2007, 87-94.

"A Poesia Angolana da Geração de 80", Luso-Brasilian Review, University of Wisconsin, vol. 33, n², 1996:19-26.

MALDONADO, Tomás. Memoria e conoscenza. Sulle sorti del sapere nella prospettiva digitale. Milano: Feltrinelli, 2005.

MATA, Inocência. "Sob o signo de uma nostalgia projectiva: a poesia angolana nacionalista e a poesia pós-colonial”, Scripta, 10(19), 2006, 25-42.

MENDES, Pedro Rosa. "O Roubo de Atlas". In Livia Apa (org. ), Angola e Mozambico: scritture della guerra e della memoria. Roma: Aracne, 2006, 71-81.

MONTICELLI, Rita "Contro-narrazioni e memorie ri-composte negli studi di genere e delle donne”. In Elena Agazzi; Vita Fortunati. Memoria e saperi: percorsi transdisciplinari. Roma: Meltemi, 605-624.

NÜNNING, Vera; Nünning, Ansgar. "Finzioni della memoria e metamemoria”. In Elena Agazzi; Vita Fortunati. Memoria e saperi: percorsi transdisciplinari. Roma: Meltemi, 2007, 564-579.

ROSÁRIO, Lourenço do. Singularidades II. Maputo: Texto Editores, 2007.

SECCO, Carmen Lúcia Tindo Ribeiro. A Magia das Letras Africanas. Rio de Janeiro: Quartet Editora, 2008.

TAVARES, Ana Paula. O Lago da Lua. Lisboa: Caminho, 1999.

_ Dizes-me coisas amargas como os frutos. Lisboa: Caminho, 2001.

_Ex-Votos. Lisboa: Caminho, 2003.

_ Manual para amantes desesperados. Lisboa: Caminho, 2007.

TRIULZI, Alessandro. Dopo la violenza. Costruzioni di memoria nel mondo contemporaneo. Napoli: L'Ancora del Mediterrâneo, 2005.

Recebido em 03 de abril e aprovado em 08 de maio de 2010. 